\title{
Characterizing $\mathrm{N}$-acetylcysteine (NAC) and $\mathrm{N}$-acetylcysteine Amide (NACA) Binding for Lead Poisoning Treatment
}

\author{
Weiqing Chen ${ }^{1}$, Nuran Ercal ${ }^{1}$, Tien Huynh ${ }^{2}$, Anatoliy Volkov², and Charles C. Chusuei ${ }^{2},{ }^{*}$ \\ ${ }^{1}$ Chemistry Department, Missouri University of Science and Technology, 142 Schrenk Hall, 400 \\ West $11^{\text {th }}$ Street, Rolla, MO 65401 \\ ${ }^{2}$ Chemistry Department, Middle Tennessee State University, Box 68, 1301 East Main Street, \\ Murfreesboro, TN 37132
}

\begin{abstract}
Using antioxidants is an important means of treating lead poisoning. Prior in vivo studies showed marked differences between various chelator antioxidants in their ability to decrease both blood $\mathrm{Pb}$ (II) levels and oxidative stress resulting from lead poisoning. The comparative abilities of NAC and NACA to $\mathrm{Pb}$ (II) were studied in vitro, for the first time, to examine the role of the $-\mathrm{OH} /-\mathrm{NH}_{2}$ functional group in antioxidant binding behavior. To assay the antioxidant-divalent metal interaction, the antioxidants were probed as solid surfaces, adsorbing $\mathrm{Pb}$ (II) onto them. Surface characterization was carried out using X-ray photoelectron spectroscopy (XPS) analysis to quantify $\mathrm{Pb}(\mathrm{II})$ in the resulting adducts. XPS of the $\mathrm{Pb} 4 \mathrm{f}$ orbitals showed that more $\mathrm{Pb}$ (II) was chemically bound to NACA than NAC. In addition, the antioxidant surfaces were probed via point-of-zero charge (PZC) measurements of NAC and NACA were obtained to gain further insight into the $\mathrm{Pb}-\mathrm{NAC}$ and $\mathrm{Pb}-\mathrm{NACA}$ binding, showing that Coulombic interactions played a partial role facilitating complex formation. The data correlated well with solution analysis of metal-ligand complexation. UV-vis spectroscopy was used to probe complexation behavior. NACA was found to have the higher binding affinity as shown by free $\mathrm{Pb}(\mathrm{II})$ available in solution after complexation from HPLC data. Electrospray ionization mass spectrometry (ESI-MS) was applied to delineate the structures of $\mathrm{Pb}$-antioxidant complexes. Experimental results were further supported by density functional theory (DFT) calculations of supermolecular interaction energies $\left(\mathrm{E}_{\text {inter }}\right)$ showing a greater interaction of $\mathrm{Pb}(\mathrm{II})$ with NACA than NAC.
\end{abstract}

\section{Keywords \\ Lead poisoning; $N$-acetylcysteine; $N$-acetylcysteine amide; isoelectric point; density functional theory}

\section{INTRODUCTION}

Lead poisoning is an ongoing world-wide concern. Lead accumulates in tissue [1] and has considerable adverse effects [2]. Lead, as a contaminant, emanates from a variety of sources, but mostly from drinking water [3]. The prevailing theory to explain the mechanism for lead

\footnotetext{
(C) 2012 Elsevier Inc. All rights reserved.

*Corresponding author: chusuei@mtsu.edu, Tel. 615-898-2079, Fax 615-494-7693.

Publisher's Disclaimer: This is a PDF file of an unedited manuscript that has been accepted for publication. As a service to our customers we are providing this early version of the manuscript. The manuscript will undergo copyediting, typesetting, and review of the resulting proof before it is published in its final citable form. Please note that during the production process errors may be discovered which could affect the content, and all legal disclaimers that apply to the journal pertain.
} 
toxicity is that $\mathrm{Pb}$ (II) oxidizes glutathione (GSH), resulting in the increase of free radicals. Since $\mathrm{Pb}(\mathrm{II})$ has a strong binding capacity for sulfhydryl proteins and enzymes, it will react with GSH to reduce the GSH-to-glutathione disulfide (GSSG) ratio, thereby causing GSH to lose its antioxidant abilities; instead, it functions as a scavenging reactive oxygen species (ROS) [4]. Chelation therapy using antioxidants is aimed at removing the accumulated lead in the body.

$\mathrm{N}$-acetyl cysteine (NAC) and N-acetyl cysteine amide (NACA) have been touted as promising therapeutic antioxidant chelator agents [5,6]. The thiol and hydroxyl (NAC) and thiol and amine (NACA) groups within these respective antioxidant molecules are known to serve as chelation sites to which divalent metal ions coordinate. The acetyl group, common to both molecules, has additional antioxidant potential due for the generation of glutathione [7]. NAC, as an antioxidant, has widely been investigated for use in treating an array of diseases, including liver failure [8-10], inflammation [11], nephropathy [12] and brain disorders $[7,13-15]$. NAC's effectiveness is primarily attributed to its ability to reduce extracellular cystine to cysteine, and as a source of sulfhydryl groups [16]. NAC stimulates glutathione synthesis, enhances glutathione-S-transferase activity, promotes liver detoxification by inhibiting xenobiotic biotransformation, and is a powerful nucleophile capable of scavenging free radicals. Its use, however, has been limited by several drawbacks, including low membrane penetration and low systemic bioavailability. However, NACA, the amide form of NAC, the carboxyl group is neutralized which makes it more hydrophobic and membrane permeable. In fact, NAC is so hydrophilic that it is not able to cross blood brain barrier. NACA, the amide form of NAC, on the other hand, has a higher cellular permeability than NAC, and therefore is considered to be a noteworthy alternative therapeutic agent [16]. For this reason, NACA has been used to treat an array oxidative stress related diseases, for example the treatment of retinal degeneration and cataract formation [17,18], oxidative stress [19], and inflammatory lung injury [20].

Despite the interest in applying these molecules for therapeutic treatment, no work to date has been done to characterize the comparative binding behavior of these molecules to divalent $\mathrm{Pb}$ (II). Very little work has been done to characterize Pb-NAC binding [21], and none whatsoever has been done to characterize Pb-NACA binding. The difficulty in assaying the complexation to obtain binding constants stem from the fact that there are multiple species present when applying Job's method, hampering solution phase analysis. This phenomenon was observed in our own experimental results (vide infra). Therefore, we have taken a surface assaying approach using photoelectron spectroscopy to quantify the amount of $\mathrm{Pb}$ (II) bound to the antioxidants. The thiol and hydroxyl (NAC) and thiol and amine (NACA) groups within these respective antioxidant molecules are known to serve as chelation sites to which divalent metal ions coordinate. The acetyl group, common to both molecules, has additional antioxidant potential due for the generation of glutathione [22]. The NAC and NACA molecules are ideal for comparative study since they differ in structure only by the $-\mathrm{NH}_{2} /-\mathrm{OH}$ functional group. Hence, differences in overall $\mathrm{Pb}$ (II) binding to the ligands are attributable to these groups (Figure 1) within the ligand structures. The relative abilities of NAC and NACA to coordinate aqueous $\mathrm{Pb}(\mathrm{II})$ were examined by probing these materials as solid surfaces to gain insight into influence of $-\mathrm{NH}_{2} /-\mathrm{OH}$ group for binding, followed by solution complexation analysis.

\section{EXPERIMENTAL}

To assay the antioxidant-divalent metal interaction, NAC and NACA were probed as solid surfaces, adsorbing $\mathrm{Pb}$ (II) on them, respectively, followed by XPS analysis to quantify adsorbed $\mathrm{Pb}$ (II) in the adducts formed. Adsorption of $\mathrm{Pb}$ (II) from aqueous solution was performed onto NAC and NACA were performed, followed by electron spectroscopy. 
(Detailed descriptions for the preparation of NAC and NACA surfaces for X-ray photoelectron spectroscopy and point-of-zero charge measurements, as well as instrumentation for solution complexation analysis and theoretical calculations are included in the Supporting Information section.) Surface characterization was complemented by solution complexation analysis. EDTA and cysteamine hydrochloride were used as standards for the Job's method using UV-vis spectroscopy and HPLC experiments, respectively, for comparative studies between NAC and NACA. Stock solutions of lead acetate and antioxidants of the same concentrations were prepared and maintained at a temperature between $0-10^{\circ} \mathrm{C}$ to prevent antioxidant decomposition just prior to analysis. The volume ratio of $\mathrm{Pb}$ (II) and antioxidants were varied from 7:1 to 1:3, according to Job's method [23]. When the volume ratio of two molecules is equal to their stoichiometric ratio, the amount of the complex formed would appear as a maximum in the UV-vis spectrum.

Point-of-zero charge (PZC) measurements of the NAC and NAC powders were conducted using the method described by Park and Regalbuto [24]. The PZC is defined as the aqueous solution $\mathrm{pH}$ value at which a solid surface has an electrostatically neutral charge. The antioxidant powders were used as the solid surface, incorporating them as supersaturated solutions, for the electrical double-layer model according to Gouy-Chapman theory.

The binding interactions of $\mathrm{Pb}$ (II) cation to NAC and NACA ligands were quantified using Density Functional Theory (DFT) [25] calculations using the Gaussian09 [26] suite of programs with Perdew-Wang 1991 exchange and correlation functionals [27,28] (Perdew, 1991; Perdew and Wang, 1992), a 6-311++G** basis set [29,30] for all ligand atoms, and a LANL2DZ basis set [31-33] for the $\mathrm{Pb}(\mathrm{II})$ cation, which uses effective core potentials (ECP) to describe core electrons. All calculations were performed using our own Linux Beowulf-type cluster equipped with $80 \times 1.86 \mathrm{GHz}$ Intel Xeon E5320 processors.

\section{RESULTS AND DISCUSSION}

XPS of the $\mathrm{Pb} 4 \mathrm{f}$ core levels were used to quantify the amount of complexed versus uncomplexed $\mathrm{Pb}$ (II) based on devonvoluted peak areas denoting these two populations. High resolution narrow scans of uncomplexed $\mathrm{Pb}$ acetate, deposited on an ultrahigh vacuum cleaned foil sample holder and outgassed via turbomolecular pump, showed oxidation states with binding energy peak centers at 138.4 (3.1) and $143.3(2.8) \mathrm{eV}$ for the $4 \mathrm{f}_{7 / 2}$ and $4 \mathrm{f}_{5 / 2}$ photoelectrons, respectively [with full-width at half maxima (fwhm) in parentheses]. In curvefitting the XPS of Pb-antioxidant complexes (Figure 1), these binding energy peak centers and fwhm denoting uncomplexed $\mathrm{Pb}$ (II) were constrained (dashed-line peak envelopes). The remaining peak envelopes were attributed to $\mathrm{Pb}$ (II) chemically bound to the antioxidants (dotted-line peak envelopes). The $\mathrm{Pb} 4 \mathrm{f}$ orbital was deconvoluted by four peak envelopes. Peaks denoted complexed $\mathrm{Pb}$ (II) for $\mathrm{Pb}-\mathrm{NAC}$ had binding energies at 140.3 (3.0) and 146.2 (3.0) eV. For the Pb-NACA complex, these oxidation states were observed at 141.2 (3.2) and 145.6 (2.9) eV. The $\mathrm{Pb} 4 \mathrm{f}$ chemical environments attributed to complexed and uncomplexed $\mathrm{Pb}$ (II), were quantified using their respective XPS integrated peak areas. The sum of XPS peak areas from complexed (dotted-line envelopes) $\mathrm{Pb}$ (II) was divided by the total sum peak areas of both complexed and uncomplexed $\mathrm{Pb}$ (II).

Integrated peak areas of chemisorbed (dotted-line peaks in Figure 2) $\mathrm{Pb} 4 \mathrm{f}$ of high resolution scans, performed in triplicate, showed $11.6 \pm 2.6 \%, 11.2 \pm 3.5 \%$ and $21.6 \pm 0.9 \% \mathrm{~Pb}$ (II) chemically bound to the EDTA, NAC and NACA antioxidants, respectively. The percentage of complexed $\mathrm{Pb}(\mathrm{II})$, shown by XPS indicated that NACA had a higher binding affinity to $\mathrm{Pb}$ (II) than both NAC and EDTA. For Pb-EDTA, $11.6 \%$ of the $\mathrm{Pb}$ (II) was complexed. For $\mathrm{Pb}-\mathrm{NAC}, 10.3 \%$ of the $\mathrm{Pb}$ (II) was complexed. For Pb-NACA, $21.6 \%$ of the $\mathrm{Pb}$ (II) was complexed, approximately twice of that for Pb-EDTA and Pb-NAC. The trend, showing a 
greater degree of binding between $\mathrm{Pb}(\mathrm{II})$ with NACA than with NAC complements the HPLC data (vide infra).

To gain insight into the role of Coulombic interactions in the binding between $\mathrm{Pb}$ (II) and the antioxidants, the isoelectric points of NAC and NACA were measured, treating them as solid surfaces in aqueous solution environments. Figure 3 shows plots of initial versus final $\mathrm{pH}$ values for both NAC and NACA. The measured PZC values, denoted by the plateaus, were found to be at $\mathrm{pH}=2.0$ and $\mathrm{pH}=5.1$ for NAC and NACA, respectively. The solution $\mathrm{pH}(=4.6)$ at which $\mathrm{Pb}-\mathrm{NAC}$ and $\mathrm{Pb}-\mathrm{NACA}$ complexations were performed was below the PZC of NACA, but higher than that of NAC. At the $\mathrm{pH}$ at which complexation of $\mathrm{Pb}$ (II) to the antioxidants occurred, NAC would adopt an overall negative charge and would be more amenable to bind $\mathrm{Pb}$ (II) while NACA would adopt an overall positive charge and repel $\mathrm{Pb}$ (II) according to the electrical double layer theory. Hence, the measured PZCs of NAC and NACA indicate that Coulombic interactions to the $-\mathrm{OH} /-\mathrm{NH}_{2}$ group only partially plays a role in governing binding between $\mathrm{Pb}(\mathrm{II})$ and the antioxidants. If this were the sole interaction, a greater binding between $\mathrm{Pb}$ and $\mathrm{NAC}$ than $\mathrm{Pb}$ and NACA would be predicted. The greater binding affinity of $\mathrm{Pb}$ (II) to NACA than to NAC, as observed by XPS and HPLC, is also incongruent with known electronegativities of the $-\mathrm{OH}$ and $-\mathrm{NH}_{2}$ functional groups, which in NAC and NACA differ in structure. Since $-\mathrm{OH}$ is the more electronegative than $-\mathrm{NH}_{2}$ based on the bond polarity index [34], a greater affinity of $\mathrm{Pb}(\mathrm{II})$ to $\mathrm{NAC}$ than $\mathrm{Pb}-\mathrm{NACA}$ binding would have been predicted; however, both HPLC and XPS results showed the opposite trend. This finding indicates that it is the interplay of a variety of interatomic forces (not electrostatic ones only) between $\mathrm{Pb}$ (II) interacting with multiple atoms within the ligand that governs the binding strength of the antioxidant chelator molecule. This rationale is further supported by DFT calculations (vide infra).

The left hand panel of Figures 4A, B and C shows raw UV-vis absorbance data of aqueous $\mathrm{Pb}$ (II) complexing with antioxidants EDTA, NAC and NACA, respectively. Actual concentrations of the $\mathrm{Pb}$ (II) substrate and antioxidant ligand to form the complexes for analysis are summarized in Table 1 . The right-hand panel shows $\mathrm{Pb}$-antioxidant complex concentrations (in arbitrary units) as a function mole fraction, $\mathrm{x}$, determined by Job's method analysis. The $\mathrm{n} / \mathrm{m}$ ratio signifies the substrate-ligand complex, $\mathrm{S}_{\mathrm{m}} \mathrm{L}_{\mathrm{n}}$. The $\mathrm{n}$ and $\mathrm{m}$ variables that represent stoichiometric numbers for the ligand and substrate, respectively, were determined by the relation, $\frac{n}{m}=\frac{x_{\max }}{1-x_{\max }}$, in which $\mathrm{x}_{\max }$ is the mole fraction of maximum complex concentration. Figure $4 \mathrm{~A}$ shows UV-vis spectra $\mathrm{Pb}-\mathrm{Na}_{4} \mathrm{EDTA}$ complexation, showing a maximum absorbance at $246 \mathrm{~nm}$. For the Pb-EDTA complex, $\mathrm{x}_{\max }$ $=0.5$, denoting a 1:1 stoichiometric ratio in good agreement with the literature [21] and validating the accuracy of our approach. Figure 4B shows the results for Pb-NAC complexation. The maximum absorbance of these spectra was observed at $275 \mathrm{~nm}$. With $\mathrm{x}_{\max }=0.286$, the stoichiometric ratio was 2.5:1 for Pb:NAC. Figure 4C show spectra for $\mathrm{Pb}$ NACA complex formation. The wavelength of maximum absorption was the same as that for $\mathrm{Pb}-\mathrm{NAC}$ complex formation, at $275 \mathrm{~nm}$. With $\mathrm{x}_{\max }=0.400$, the ratio $\mathrm{Pb}$-to-NACA in the complex was found to be 1.5:1. Non-unity stoichiometries for Pb-NAC and Pb-NACA denoted more than one complex being formed as $\mathrm{Pb}(\mathrm{II})$ interacted with the NAC and NACA antioxidants; hence, bingind contant determination for these complexes were hampered. Substrate-to-ligand ratios in the complexes formed for Pb-NAC and Pb-NACA differed, giving further support that there is substantially dissimilar coordination behavior between $\mathrm{Pb}(\mathrm{II})$ and the two antioxidants.

To gain insight into the structures of these complexes, ESI-MS was performed to detect and characterize the $\mathrm{Pb}$-antioxidant mass spectral (MS) cracking fragments. Major complexes examined were those of the Pb-EDTA (used as a standard), Pb-NAC and Pb-NACA 
complexes. Figure 5A shows the signal emanating from [ $\mathrm{Na}_{3}$ EDTA-Pb]+ at $565.09 \mathrm{~m} / \mathrm{z}$, in agreement with the expected 1:1 ratio of the Pb-EDTA complex in the UV-vis experiments; this was the only predominant fragment observed [21]. Figure 5B shows the MS patterns of the $\mathrm{Pb}-\mathrm{NAC}$ complex. Four MS fragments were detected, indicating that $\mathrm{Pb}(\mathrm{II})$ coordinated to NAC with metal-to-ligand ratios of 1:1, 2:1, 2:2, and 3:2. Masses were observed from $[\mathrm{Pb}-\mathrm{NAC}]^{+}$at $\mathrm{m} / \mathrm{z}=369.77 \mathrm{~m} / \mathrm{z},\left[\mathrm{Pb}-\mathrm{NAC}-\mathrm{Pb}-\mathrm{H}_{2} \mathrm{O}\right]+$ at $\mathrm{m} / \mathrm{z}=591.82$, [NAC-Pb-NAC-Pb] ${ }^{+}$ at $\mathrm{m} / \mathrm{z}=736.80$, and $[\mathrm{Pb}-\mathrm{NAC}-\mathrm{Pb}-\mathrm{NAC}-\mathrm{Pb}]^{+}$at $\mathrm{m} / \mathrm{z}=942.73$; the percent mole fractions for all of these species were $76.5 \%, 14.5 \%, 6.5 \%$, and $2.5 \%$, respectively. In contrast to the $\mathrm{Pb}-\mathrm{NAC}$ binding, only three major MS fragments were observed in the Pb-NACA complexation according to ESI-MS (Figure 5C). One signal emanated from [Pb-NACA-H $]^{+}$ at $\mathrm{m} / \mathrm{z}=368.93$. Two other peaks were observed at $\mathrm{m} / \mathrm{z}=529.08$ and $\mathrm{m} / \mathrm{z}=575.04$, denoting $[\mathrm{Pb}-(\mathrm{NACA}-\mathrm{NACA})-\mathrm{H}]^{+}$and $[\mathrm{Pb}-\mathrm{NACA}-\mathrm{Pb}]^{+}$. Mole fraction percent

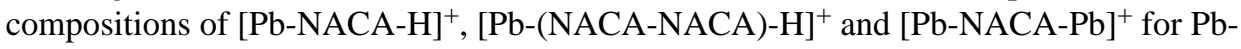
NAC complexation were $92.2 \%, 4.8 \%$ and $3.0 \%$, respectively. In the cases of both $\mathrm{Pb}-\mathrm{NAC}$ and $\mathrm{Pb}-\mathrm{NACA}$ coordination interactions, the 1:1 substrate-to-ligand ratio was the most dominant stoichiometry for $\mathrm{Pb}$-antioxidant coordination. Multiple $\mathrm{Pb}$ atom species detected by ESI-MS correlates with the high $\mathrm{Pb}$-to-antioxidant ratios observed in the Job's method data (Figures 4B and 4C). Although the Pb:antioxidant ratios could not be directly quantified from percent mass spectral abundances, the presence of higher $\mathrm{Pb}$-to-ligand ratio fragments for Pb-NAC than Pb-NACA is consistent with observed n/m ratios in the Job's method experiments.

Cysteamine hydrochloride, NAC and NACA are mono-thiol antioxidants that contain a sulfur-hydrogen functional group. Chelating ability was determined and evaluated by quantifying the percentage of $\mathrm{Pb}$ (II) coordinated to the antioxidants, and HPLC was applied to determine the amount of antioxidants that had been coordinated. The retention times for NAC, NACA and cysteamine were 4.8, 5.2 and $17.2 \mathrm{~min}$, respectively. Figure 6 shows the declining trend of cysteamine with an increase of $\mathrm{Pb}$ acetate concentration. With addition of $\mathrm{Pb}(\mathrm{II})$ acetate, the decrease in free cysteamine, NAC, and NACA in the substrate-ligand complexes became more pronounced (Table 2). At a 1:1 ratio of $\mathrm{Pb}$ :cysteamine, there was a $19.0 \%$ decrease in the free cysteamine concentration (compared to the control that contained only the ligand) with zero incubation time, and a $33.5 \%$ decline after a 1-hr incubation in $37.0^{\circ} \mathrm{C}$ water-bath. This decrease in free cysteamine is attributed to antioxidant decomposition at physiological temperature, which were also observed for NAC and NACA. At a 1:1 ratio of $\mathrm{Pb}$-to-NAC, there was $10.1 \%$ decrease in free NAC in solution upon its interaction with $\mathrm{Pb}(\mathrm{II})$ at no incubation; after a 1-hr incubation, there was $15.5 \%$ decrease of free NAC. For the Pb-NACA complex, there was a $21.7 \%$ decrease in free NACA at zero incubation and a $28.7 \%$ decrease after a $1-\mathrm{hr}$ incubation. HPLC data showed the relative amounts of free ligands complexing to $\mathrm{Pb}(\mathrm{II})$ in the following descending order: NAC > NACA > cysteamine. From the decrease in free antioxidant in solution, the data set indicated that a relatively greater proportion of NACA coordinated to $\mathrm{Pb}(\mathrm{II})$ as compared to $\mathrm{NAC}$, i.e., NACA had a greater affinity for $\mathrm{Pb}(\mathrm{II})$ than NAC.

In the DFT calculations, approximately two dozen possible metal-ligand structures for each coordination were calculated, with inter-atomic distances between the $\mathrm{Pb}$ (II) atom and the nearest $(1 \mathrm{NN})$, second $(2 \mathrm{NN})$, third $(3 \mathrm{NN})$, fourth $(4 \mathrm{NN})$ and fifth $(5 \mathrm{NN})$ nearest neighbor atoms reported. The presence of the $-\mathrm{OH} /-\mathrm{NH}_{2}$ functional groups affected the optimized geometries of the divalent metal with ligands, and subsequently the overall $\mathrm{Pb}$ (II) interactions with multiple atoms within the antioxidant. There were a total of twenty four possible structures for NAC-Pb (Table S1) and twenty three possible structures for $\mathrm{Pb}$ NACA (Tables S1 and S2, respectively, shown in the Supporting Information section). Interatomic distances between $\mathrm{Pb}$ (II) atom and the first five nearest neighbors are listed along with its intermolecular interaction binding energy $\left(E_{i n t e r}\right)$, the energy needed to 
remove the metal atom from each cluster in the data tables. In addition to atomic level electrostatic interaction energies, the calculated stabilization energy denoted in $E_{\text {inter }}$ includes contributions from dispersion, induction and exchange repulsion energies between the $\mathrm{Pb}$ (II) and its nearest neighbors, which are not fully accounted for by the relative electronegativities of the $-\mathrm{OH} /-\mathrm{NH}_{2}$ groups within the NAC and NACA molecules or isoelectric points of these ligands alone. The average $\mathrm{E}_{\text {inter }}$ for $\mathrm{Pb}-\mathrm{NAC}$ and $\mathrm{Pb}-\mathrm{NACA}$ were found to be $-4.7 \pm 1.2 \mathrm{eV}$ and $-5.1 \pm 1.5 \mathrm{eV}$, respectively (Tables $\mathrm{S} 1$ and $\mathrm{S} 2$ ), confirming that $\mathrm{Pb}(\mathrm{II})$ has a greater binding affinity for NACA than NAC.

Questions regarding the PZC data not only provided motivation for the DFT calculations, they (Figure 2) also reveal an additional insight into a property of NAC and NACA, influenced by the $-\mathrm{OH} /-\mathrm{NH}_{2}$ functional group. The isoelectric point of NACA $(\mathrm{PZC}=5.1)$ is closer to cytoplasm $\mathrm{pH}(=7.2-7.4)$ than that of NAC $(\mathrm{PZC}=2.0)$, hence making NACA more amenable to traverse cell membranes. Therefore, compared to NAC, NACA, in addition to having a greater binding affinity for $\mathrm{Pb}(\mathrm{II})$, may be the better ligand to treat lead poisoning due to a greater propensity to remove intracellular $\mathrm{Pb}$ (II) across membranes.

\section{CONCLUSIONS}

In summary, the solution complexation data correlated well with the surface analysis assays provided by XPS and isoelectric point measurements. UV-vis Job's method data indicated multiple complexes present as $\mathrm{Pb}$ (II) coordinated with the NAC and NACA, respectively, which was supported by ESI-MS data. Fragmentation patterns for Pb-NAC and Pb-NACA showed four complexes in the Pb-NAC sample with metal-to-ligand ratios of 1:1, 2:1, 2:2, and 3:2. For Pb-NACA, metal-to-ligand ratios of 1:1, 2:1 and 2:2 were observed. Among both metal-to-ligand coordinations, the 1:1 ratio was the most abundant as observed by ESIMS. The presence of fewer complexes in the Pb-NACA coordination as compared to $\mathrm{Pb}$ NAC suggests a greater stability complex formation for $\mathrm{Pb}(\mathrm{II})$ interactions with NACA. Both HPLC and XPS of the $\mathrm{Pb} 4 \mathrm{f}$ core levels showed a greater population of chemically bound $\mathrm{Pb}(\mathrm{II})$ to the antioxidants than unbound $\mathrm{Pb}$ (II), i.e., unreacted $\mathrm{Pb}$ (II), for $\mathrm{Pb}-\mathrm{NACA}$ than Pb-NAC. PZC measurements of NAC (2.0) and NACA (5.1), indicated that electrostatic effects from the $-\mathrm{OH} /-\mathrm{NH}_{2}$ moieties alone (consistent with the known polarizabilities of these groups) only partially accounted for the greater Pb-NACA binding, compared to $\mathrm{Pb}-\mathrm{NAC}$. These in vitro findings in this study will serve as an important benchmark for engineering improved therapeutic antioxidant chelators for the treatment of lead poisoning. DFT calculations of the $\mathrm{E}_{\mathrm{inter}}$ binding energies showed that the interplay of (1) electrostatic interactions, (2) dispersion, (3) induction and (4) exchange repulsion energies accompanying the optimized geometries of the metal-ligand structures governed the observed, enhanced $\mathrm{Pb}-\mathrm{NACA}$ binding. Regarding the precise mechanism governing $\mathrm{Pb}-$ antioxidant binding, the precise role of each of these contributions for metal-ligand binding is under currently under investigation in a more rigorous theoretical calculation study. Our current findings suggest that the collective contributions of (2), (3) and (4) is more substantial as compared to (1) alone.

\section{Supplementary Material}

Refer to Web version on PubMed Central for supplementary material.

\section{Acknowledgments}

This work was sponsored by the National Institutes of Health Academic Research Enhancement Award Grant (2R15ES012167-02A1) and in part by the Faculty Research and Creative Activity Committee (FRCAC) of Middle Tennessee State University. We thank Dr. Nathan Leigh for the use of the mass spectrometry facility at the University of Missouri-Columbia and helpful discussions. 


\section{References}

1. Hu H, Rabinowitz M, Smith D. Bone as a biological marker in epidemiologic studies of chronic toxicity: conceptual diagrams. Environ Health Perspect. 1998; 106:1-8. [PubMed: 9417769]

2. Mudipalli A. Lead hepatotoxicity and potential health effects. Indian J Med Res. 2007; 126:518527. [PubMed: 18219078]

3. Patrick L. Lead toxicity, A review of the literature. Part I: exposure, evaluation, and treatment. Altern Med Rev. 2006; 11:2-22. [PubMed: 16597190]

4. Gurer H, Ercal N. Can antioxidants be beneficial in the treatment of lead poisoning? Free Rad Biol Med. 2000; 29:927-945. [PubMed: 11084283]

5. Aykin-Burns N, Franklin EA, Ercal N. Effects of N-Acetylcysteine on lead-exposed PC-12 cells. Arch Environ Contam Toxicol. 2005; 49:119-123. [PubMed: 15981033]

6. Penugonda S, Mare S, Lutz P, Banks WA, Ercal N. Potentiation of lead-induced cell death in PC12 cells by glutamate: Protection by $\mathrm{N}$-acetylcysteine amide (NACA), a novel thiol antioxidant. Toxicol Appl Pharmacol. 2006; 216:197-205. [PubMed: 16781745]

7. Berk M, Dean O, Cotton SM, Gama CS, Kapczinski F, Fernandes BS, Kohlmann K, Jeavons S, Hewitt K, Allwang C, Cobb H, Bush AI, Schapkaitz I, Dodd S, Malhi GS. The efficacy of N-acetyl cysteine as a adjunctive treatment in biopolar depression: an open label trial. J Affect Disord. 2011; 135:389-394. [PubMed: 21719110]

8. Morsy MA, Abdalla AM, Mahmoud AM, Abdelwahab SA, Mahmoud ME. Protective effects of curcumain, alpha-lipoic acid, and $\mathrm{N}$-acetylcysteine against carbon tetrachloride-induced liver fiobrosis in rats. J Physiol Biochem. 2011; 10 in press.

9. Odewumi CO, Badisa VL, Le UT, Latinwo LM, Ikediobi CO, Badisa RB, Darling-Reed SF. Protective effects of $\mathrm{N}$-acetylcysteine against cadmium-induced damage in cultured rat normal liver cells. Int J Mol Med. 2011; 27:243-248. [PubMed: 21125209]

10. Sotelo N, de los Angeles Duranzo M, Gonzalez A, Dhanakotti N. Early treatment with Nacetylcysteine in children with acute liver failure secondary to hepatitis A. Ann Hepatol. 2009; 8:353-358. [PubMed: 20009135]

11. Palacio JR, Markert UR, Martínez P. Anti-inflammatory properties of N-acetylcysteine on lipopolysaccharide-activated macrophages. Inflamm Res. 2011; 60:695-704. [PubMed: 21424515]

12. Awal A, Ahsan SA, Siddique MA, Banerjee S, Hasan MI, Saman SM, Arzu J, Subedi B. Effect of hydration with or without $\mathrm{N}$-acetylcysteine on contrast induced nephrophaty in patients undergoing coronary angiography and percutaneous coronary intervention. Mymensing Med J. $2011 ; 20: 264-269$.

13. Robinson RA, Joshi G, Huang Q, Sultana R, Baker AS, Cai J, Pierce W, St Clair DK, Markesbery WR, Butterfield DA. Proteomic analysis of brain proteins in APP/PS-1 human double mutant knock-in mice with increasing amyloid $\beta$-peptide deposition: insights into the effects of in vivo treatment with $\mathrm{N}$-acetylcysteine as a potntial therapeutic intervention in mild cognitive impairment and Alzheimer's disease. Proteomics. 2011; 11:4243-4256. [PubMed: 21954051]

14. Jain S, Kumar CH, Suranagi UD, Mediratta PK. Protective effect of N-acetylcysteine on bisphenol A-induced cognitive dysfunction and oxidative stress in rats. Food Chem Toxicol. 2011; 49:14041409. [PubMed: 21440025]

15. Berman AE, Chan WY, Brennan AM, Reyes RC, Adler BL, Suh SW, Kauppinen TM, Edling Y, Swanson RA. N-acetylcysteine prevents loss of dopaminergic neurons in the EACC1 -/- mouse. Ann Neurol. 2011; 69:509-520. [PubMed: 21446024]

16. Whillier S, Raftos JE, Chapman B, Kuchel PW. Role of N-acetylcysteine and cystine in glutathione synthesis in human erythrocytes. Redox Rep. 2009; 14:115-124. [PubMed: 19490753]

17. Carey JW, Pinarci EY, Penugonda S, Karacal H, Ercal N. In vivo inhibition of 1-buthionine-(S,R)sulfoximine-induced cataracts by a novel antioxidant, N-acetylcysteine amide. Free Rad Biol Med. 2011; 50:722-729. [PubMed: 21172425]

18. Schimel AM, Abraham L, Cox D, Sene A, Kraus C, Dace DS, Ercal N, Apte RS. N-acetyl cysteine amide (NACA) prevents retinal degeneration by up-regulating reduced glutathione production and reversing lipid peroxidation. Am J Pathol. 2011; 178:2032-2043. [PubMed: 21457933] 
19. Penugonda S, Ercal N. Comparative evaluation of N-acetylcysteine (NAC) and N-acetylcysteine amide (NACA) on glutamate and lead-induced toxicity in CD-1 mice. Toxicol Lett. 2011; 201:2032-2043.

20. Lee KS, Kim SR1, Park HS, Park SJ, Min KH, Lee KY, Choe YH, Hong SH, Han HJ, Le YR, Kim JS, Atlas D, Lee YC. A novel thiol compound, N-acetylcysteine amide, attenuates allergic airway disease by regulating activation of NF-kappaB and hypoxia-inducible factor-1alpha. Exp Mol Med. 2007; 39:755-759.

21. Gupta VK, Jain AK, Maheshwari G. Synthesis, characterization and Pb(II) ion selectivity of N, $\mathrm{N}^{\prime}$ bis(2-hydroxyl-1-napthalene)-2,6-pyridiamine(BHNPD). Int J Electrochem Sci. 2007; 2:102-112.

22. Flora SJS. Structural, chemical and biological aspects of antioxidants for strategies against metal and metalloid exposure. Oxid Med Cell Longev. 2009; 1:191-206. [PubMed: 20716905]

23. MacCarthy P, Mark HB Jr. An evaluation of Job's method of continuous variations as applied soil organic matter-metal ion interactions. Soil Sci Soc Am J. 1976; 40:267-276.

24. Park J, Regalbuto JR. A Simple, Accurate Determination of Oxide PZC and the Strong Buffering Effect of Oxide Surfaces at Incipient Wetness. J Colloid Interface Sci. 1995; 175:239-252.

25. Hohenberg P, Kohn W. Inhomogeneous electron gas. Phys Rev. 1964; 136:B864-B871.

26. Frisch, MJ.; Trucks, GW.; Schlegel, HB.; Scuseria, GE.; Robb, MA.; Cheeseman, JR.; Scalmani, V.; Barone, V.; Menakatsuji, H.; Mennucci, B.; Petersson, GA.; Caricato, M.; Li, X.; Hratchian, HP.; Izmaylov, AF.; Bloino, J.; Zheng, G.; Sonnenberg, JL.; Hada, M.; Ehara, M.; Toyota, K.; Fukuda, R.; Hasagawa, J.; Ishida, M.; Nakajima, T.; Honda, Y.; Kitao, O.; Nakai, H.; Vreven, T.; Montgomery, JA., Jr; Peralta, JE.; Ogliaro, F.; Bearpark, M.; Heyd, JJ.; Brothers, E.; Kudin, KN.; Staroverov, VN.; Kobayashi, R.; Normand, J.; Raghavachari, K.; Rendell, A.; Burant, JC.; Iyengar, SS.; Tomasi, J.; Cossi, M.; Rega, N.; Millam, JM.; Klene, M.; Knox, JE.; Cross, JB.; Bakken, V.; Adamo, C.; Jaramillo, J.; Gomperts, R.; Stratmann, RE.; Yazyev, O.; Austin, AJ.; Cammi, R.; Pomelli, C.; Ochterski, JW.; Martin, RL.; Morokuma, K.; Zakrzewski, VG.; Voth, GA.; Salvador, P.; Dannenberg, JJ.; Dapprich, S.; Daniels, AD.; Farkas, Ö.; Foresman, JB.; Ortiz, JV.; Cioslowski, J.; Fox, DJ. Gaussian, Inc. CT: 2009.

27. Perdew, JP. Electronic Structure of Solids '91. Ziesche, P.; Eschrig, H., editors. Akademie Verlag; Berlin: 1991.p. 11

28. Perdew JP, Wang Y. Accurate and simple analytic representation of the electron gas correlation energy. Phys Rev B. 1992; 45:13244-13249.

29. Raghavachari K, Binkley JS, Seeger R, Pople JA. Self-consistent molecular orbital methods. 20. Basis set for correlated wave-functions. J Chem Phys. 1980; 72:650-654.

30. McLean AD, Chandler GS. Contracted Gaussian-basis sets for molecular calculations. 1. 2nd row atoms, Z=11-18. J Chem Phys. 1980; 72:5639-5648.

31. Hay PJ, Wadt WR. Ab initio effective core potentials for molecular calculations - potentials for the transition-metal atoms Sc to Hg. J Chem Phys. 1985; 82:270-283.

32. Hay PJ, Wadt WR. Ab initio effective core potentials for molecular calculations - potentials for K to Au including the outermost core orbitals. J Chem Phys. 1985; 82:299-310.

33. Wadt WR, Hay PJ. Ab initio effective core potentials for molecular calculations: potentials for main group elements Na to Bi. J Chem Phys. 1985; 82:284-298.

34. Reed LH, Allen LC. Bond polarity index: application to group electronegativity. J Phys Chem. 1992; 96:157-164. 
(1)<smiles>CC(=O)NCC(CS)C(=O)O</smiles>

(18)

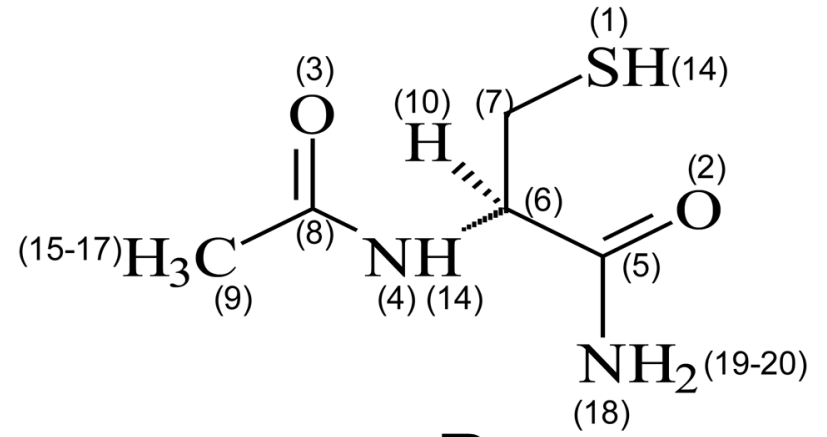

B

Figure 1.

Structural formulas for (A) N-acetyl cysteine (NAC); and (B) N-acetyl cysteine amide (NACA). Numeric assignments for each atom shown correspond to atomic positions used for DFT calculations. Hydrogen atoms attached to $\mathrm{C}(7)$ were assigned as $\mathrm{H}(11)$ and $\mathrm{H}(12)$. 


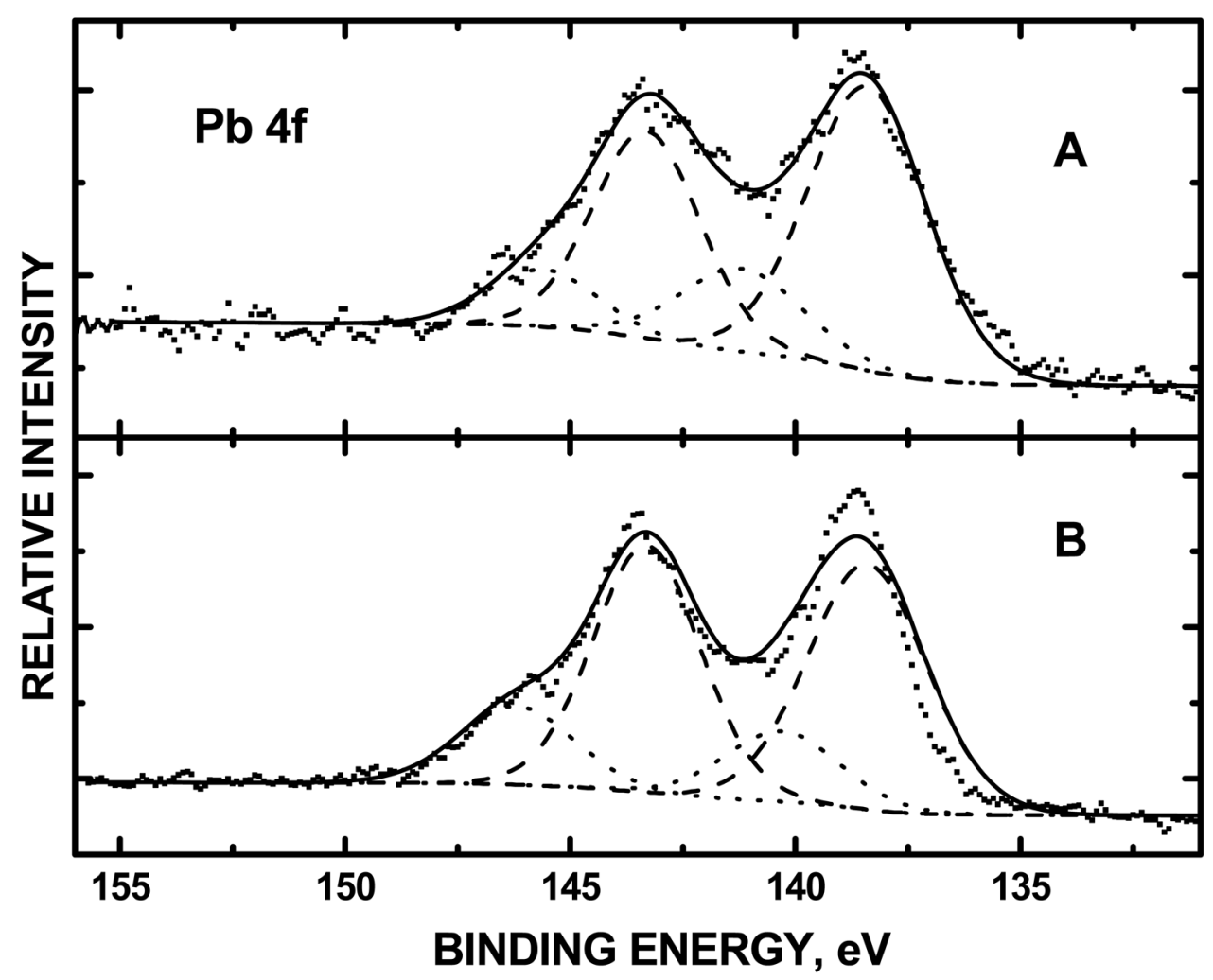

Figure 2.

XPS Pb 4f spectra of (A) Pb-NAC; and (B) Pb-NACA. Dotted-line envelope denotes Pb(II) chemically bound to NAC while the dashed-lined envelope denoted uncomplexed $\mathrm{Pb}$ acetate. 


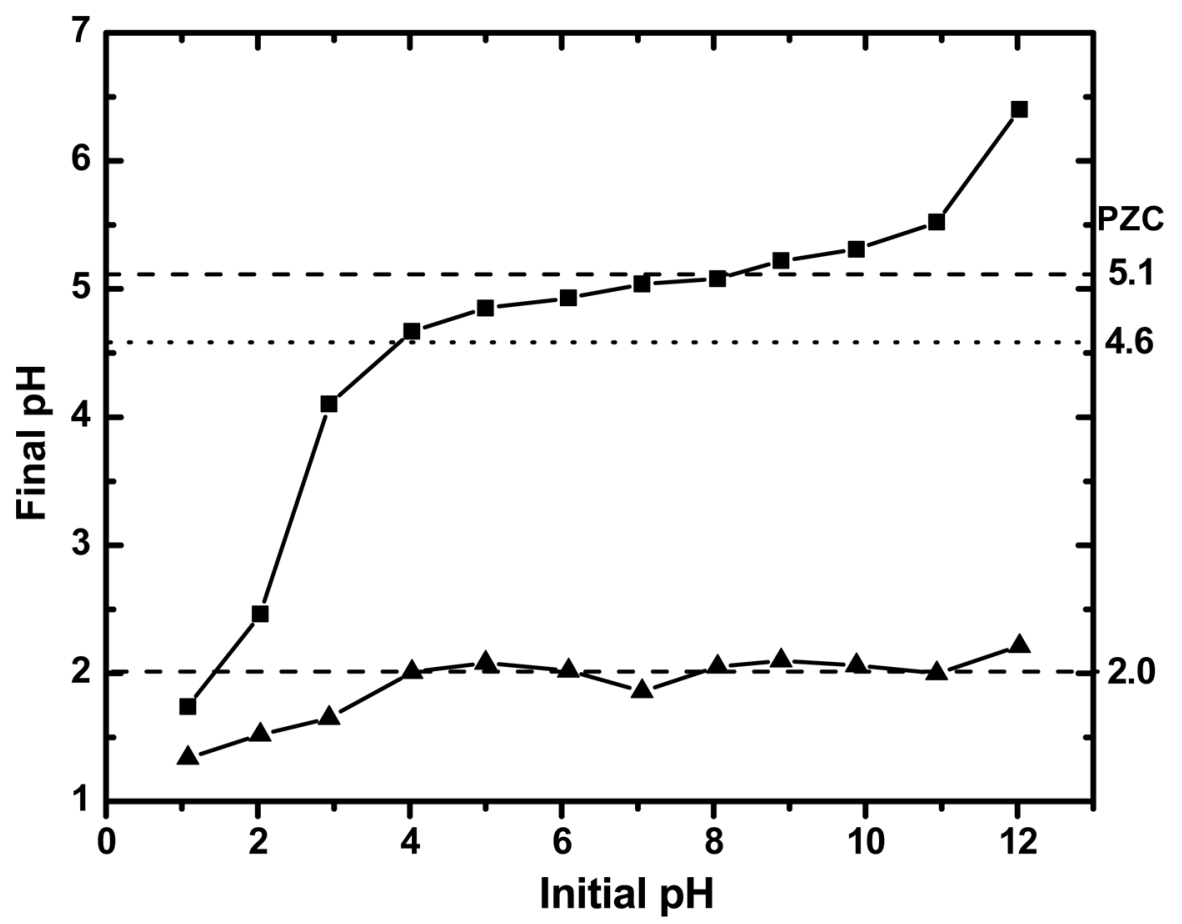

Figure 3.

PZC Plots for NAC and NACA. Plateaus denote the observed PZC for NAC and NACA at 2.0 and 5.1, respectively. The $\mathrm{pH}$ at 4.6 (horizontal dotted line) denotes aqueous solution conditions at which $\mathrm{Pb}-\mathrm{NAC}$ and $\mathrm{Pb}-\mathrm{NACA}$ complexations occurred. 

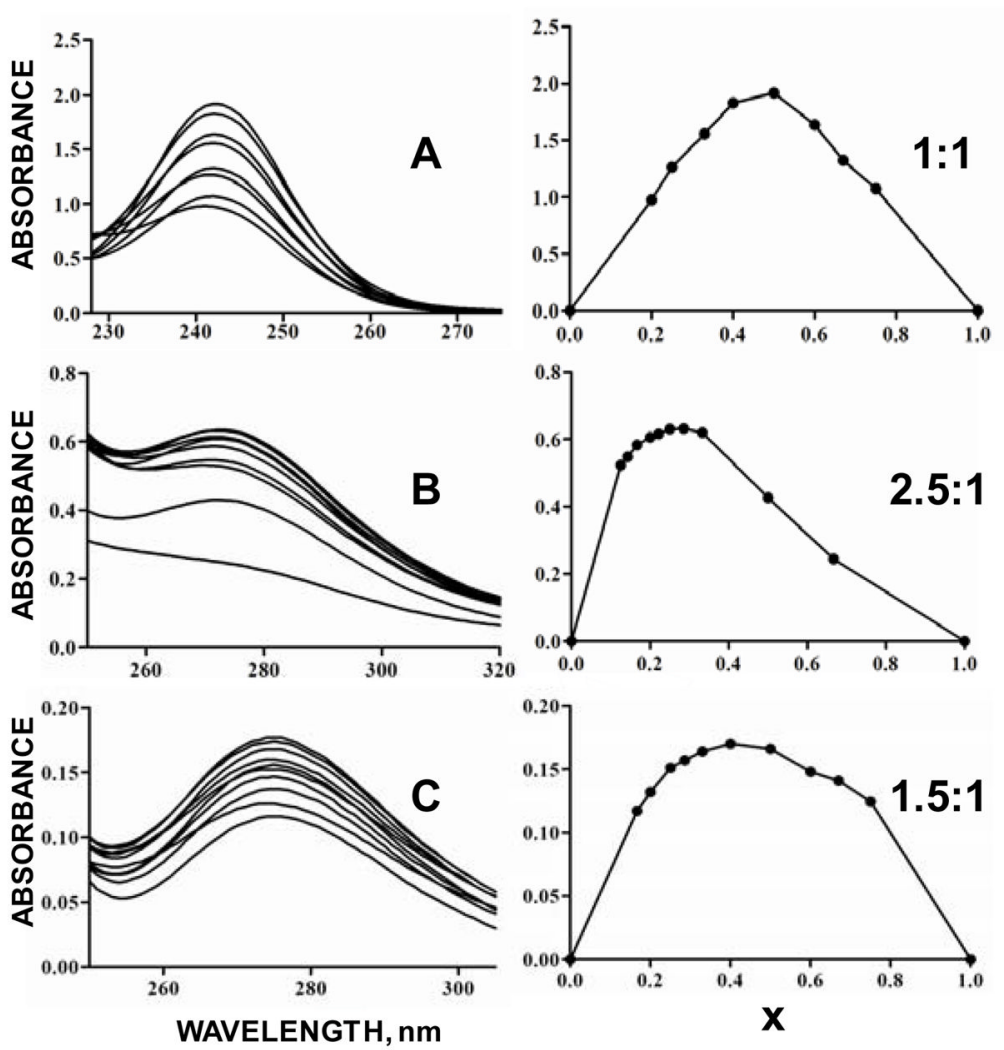

Figure 4.

Raw UV-vis spectral data (left-hand panel) and Job's method plots (right-hand panel) Pbantioxidant complexes. (A) The wavelength of maximum aborbance $\left(\mathrm{x}_{\max }\right)$ for Pb-EDTA was $246 \mathrm{~nm}$ with a metal-ligand stoichiometric ratio of $1: 1$; (B) the highest $\mathrm{x}_{\max }$ for $\mathrm{Pb}$ NAC was at $275 \mathrm{~nm}$, with a 2.5:1 ratio; and (C) the $\mathrm{x}_{\max }$ for Pb-NACA was at $275 \mathrm{~nm}$ with a 1.5:1 stoichiometric ratio. 

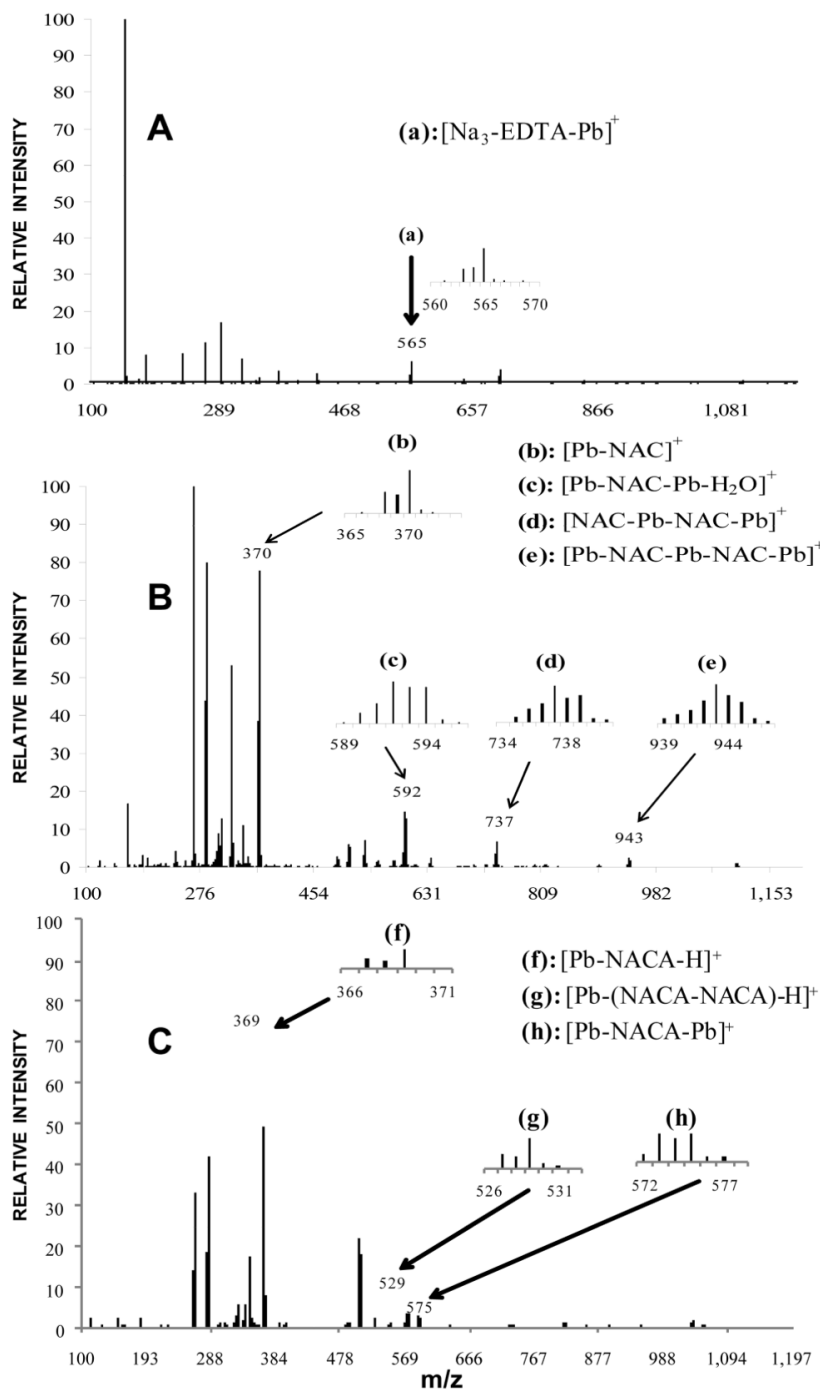

Figure 5.

ESI-MS cracking pattern of (a) Pb-EDTA solution; (b) Pb-NAC; and (c) Pb-NACA. 


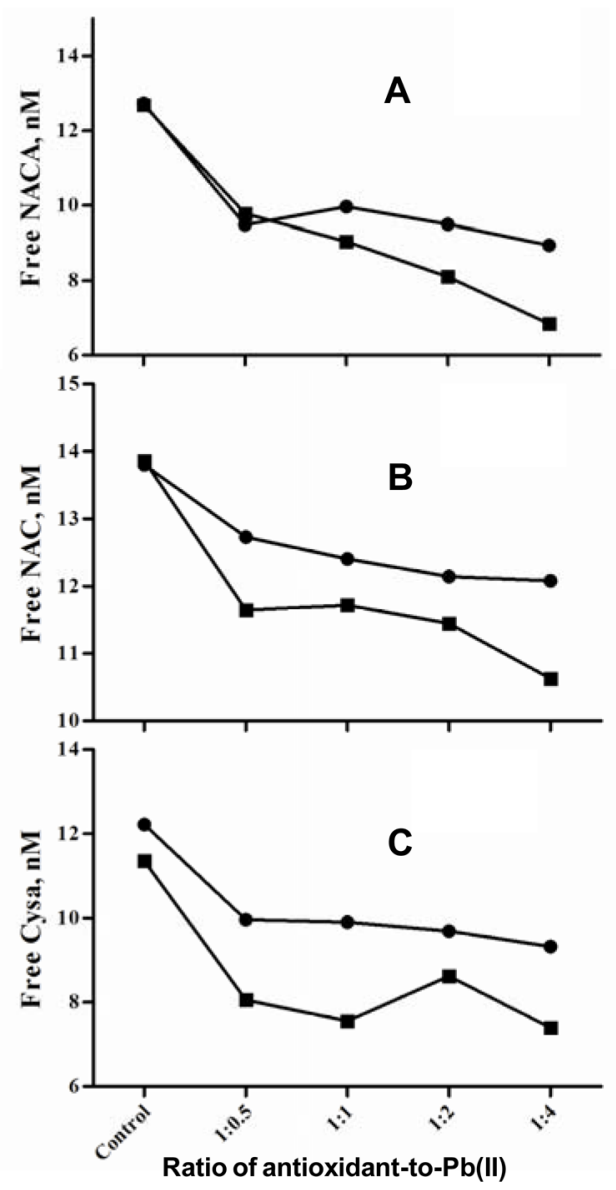

Figure 6.

HPLC data showing free antioxidants in solution with increasing $\mathrm{Pb}$ acetate concentrations added. The control group contained only the respective antioxidants at $12.5 \mathrm{nM}$ concentration. Samples from which HPLC data were obtained were comprised of $12.5 \mathrm{nM}$ of antioxidant, with increasing $\mathrm{Pb}$ acetate concentrations of $6.25,12.5,25.0$ and $50.0 \mathrm{nM}$, respectively. (A) Pb-NACA solutions; (B) Pb-NAC solutions; and (C) Pb-cysteamine hydrochloride solutions. 
TABLE 1

Composition of Pb-antioxidant complexes obtained from ESI-MS

\begin{tabular}{cccc}
\hline Ligand & Mass-to-charge ratio $(\mathbf{m} / \mathbf{z})$ & Fragment & Percent abundance \\
\hline $\mathrm{Na}_{4} \mathrm{EDTA}$ & 565.09 & {$\left[\mathrm{Na}_{3}-\mathrm{EDTA}-\mathrm{Pb}\right]+$} & $100 \%$ \\
$\mathrm{NAC}$ & 369.77 & {$[\mathrm{~Pb}-\mathrm{NAC}]^{+}$} & $76.5 \%$ \\
& 591.82 & {$\left[\mathrm{~Pb}-\mathrm{NAC}-\mathrm{Pb}-\mathrm{H}_{2} \mathrm{O}\right]+$} & $14.5 \%$ \\
& 736.80 & {$[\mathrm{NAC}-\mathrm{Pb}-\mathrm{NAC}-\mathrm{Pb}]^{+}$} & $6.5 \%$ \\
& 942.73 & {$[\mathrm{~Pb}-\mathrm{NAC}-\mathrm{Pb}-\mathrm{NAC}-\mathrm{Pb}]^{+}$} & $2.5 \%$ \\
\multirow{2}{*}{$\mathrm{NACA}$} & 368.93 & {$[\mathrm{~Pb}-\mathrm{NACA}-\mathrm{H}]^{+}$} & $92.2 \%$ \\
& 529.08 & {$[\mathrm{~Pb}-(\mathrm{NACA}-\mathrm{NACA})-\mathrm{H}]^{+}$} & $4.8 \%$ \\
& 575.04 & {$[\mathrm{~Pb}-\mathrm{NACA}-\mathrm{Pb}]^{+}$} & $3.0 \%$ \\
\hline
\end{tabular}


